\section{A supramolecular peptide nanofiber templated Pd nanocatalyst for efficient Suzuki coupling reactions under aqueous conditions $\dagger$}

\author{
Mohammad Aref Khalily, $\ddagger$ Oya Ustahuseyin, $\ddagger$ Ruslan Garifullin, Rukan Genc and \\ Mustafa O. Guler*
}

Received 27th August 2012, Accepted 4th October 2012

DOI: $10.1039 / \mathrm{c} 2 \mathrm{cc} 36228 \mathrm{~g}$

A bioinspired peptide amphiphile nanofiber template for formation of one-dimensional Pd nanostructures is demonstrated. The Pd and peptide nanocatalyst system enabled efficient catalytic activity in Suzuki coupling reactions in water at room temperature. The nanocatalyst system can be easily separated and reused in successive reactions without significant loss in activity and structural integrity.

Metal nanostructures are attractive catalysts for a wide variety of organic reactions due to increased accessibility to surface atoms and lower coordination numbers compared to bulk equivalents, which result in enhanced catalytic activity. ${ }^{1}$ Palladium nanoparticles have been used as catalysts for $\mathrm{C}-\mathrm{C}$ coupling such as Suzuki and Heck reactions as a suspension or adsorbed onto a support i.e. carbon structures, ${ }^{2}$ dendrimers, ${ }^{3}$ polymers, ${ }^{4}$ metal-organic frameworks ${ }^{5}$ and mesoporous silica. ${ }^{6}$ In most cases, solid support materials provide easy separation and enable reuse of the catalyst. Catalytic activity of palladium nanoparticles is further enhanced by employing nanoscale template directed synthesis providing high surface area nanoparticles. ${ }^{7,8}$ However, not only the catalyst performance is important, but also environmental concerns should be taken into account during development of novel catalysts. ${ }^{9}$ The research for environmentally friendly chemical synthesis led to a search for catalytic reactions in cheap, readily available, non-toxic, non-flammable and environmentally friendly solvents such as water at room temperature. ${ }^{10}$ Suzuki-Miyaura reactions in water with improved yield and a simple reaction protocol still remain a major challenge. In general, various additives such as phosphine ligands and quaternary ammonium salts such as tetrabutylammonium bromide (TBAB) or cetyltrimethylammonium bromide (CTAB) are required for effective reaction progress in aqueous media. ${ }^{11,12}$ These additives lower the atom economy of the reaction and produce extra waste products.

Biological template materials (e.g. peptides, proteins, viruses, and bacteria) in the synthesis of catalytic metal nanostructures

Institute of Materials Science and Nanotechnology, National Nanotechnology Research Centre (UNAM), Bilkent University, Ankara,Turkey06800.E-mail: moguler@unam.bilkent.edu.tr; Fax: +90 312266 4365; Tel: + 903122903552

$\dagger$ Electronic supplementary information (ESI) available: Experimental details for synthesis and characterization of the peptide amphiphile molecule and the Pd-peptide system. See DOI: 10.1039/c2cc36228g

$\ddagger$ These authors contributed equally. are of great interest because of their versatile chemical and physical properties. ${ }^{13}$ A few studies previously reported heterogeneous palladium catalysts, which were synthesized by a nanoscale and environmentally friendly template for $\mathrm{C}-\mathrm{C}$ coupling reactions. ${ }^{14}$ Self-assembled peptide amphiphile (PA) nanofibers are promising candidates as a template and support owing to their tailorable surface properties. By employing metal-binding amino acids in PA structure (e.g. lysine, glutamic acid and DOPA), peptide nanofibers can specifically bind metal ions for functional material applications. ${ }^{15,16}$ These bioinspired peptide nanostructures can be further exploited for seeding and nucleation of metal ions for producing nanoscale inorganic nanostructures. $^{15}$

Herein, we report bioinspired supramolecular peptide nanofiber templated $\mathrm{Pd}^{0}$ hybrid nanocatalyst (Pd@Peptide) for mild and efficient Suzuki-Miyaura coupling reactions in aqueous media at room temperature without additives. The efficiency of the Pd@Peptide nanocatalyst system was demonstrated by successful application in a variety of reagents. In this study, we designed and synthesized a de novo peptide amphiphile molecule (Lauryl-VVAGHH-Am (Fig. S1, ESI $\dagger$ )) that can coordinate to $\mathrm{Pd}^{\mathrm{II}}$ ions through lone pair electrons in imidazole moieties of histidine residues in the peptide (Scheme 1). ${ }^{17}$

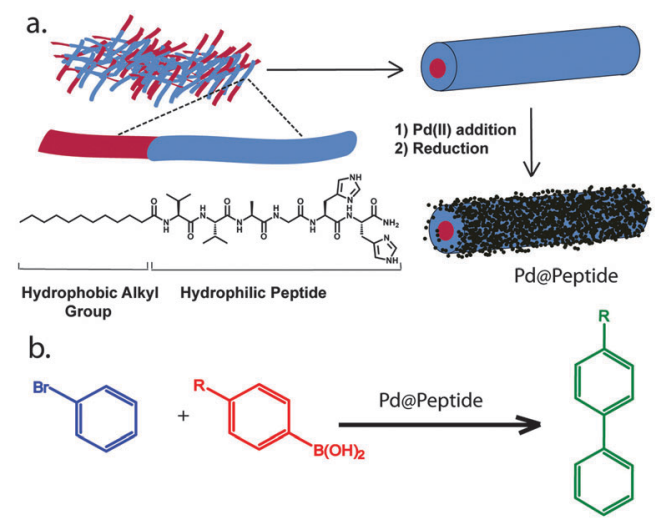

Scheme 1 (a) Self-assembly of peptide amphiphile molecules generates nanofibers with $10 \mathrm{~nm}$ diameter. Seeding and reduction of $\mathrm{Pd}^{\mathrm{II}}$ ions on the surface of peptide nanofibers form hybrid peptide and $\mathrm{Pd}^{0}$ nanostructures (Pd@Peptide). (b) Pd@Peptide nanostructures can be used as catalyst in $\mathrm{C}-\mathrm{C}$ coupling reactions. 


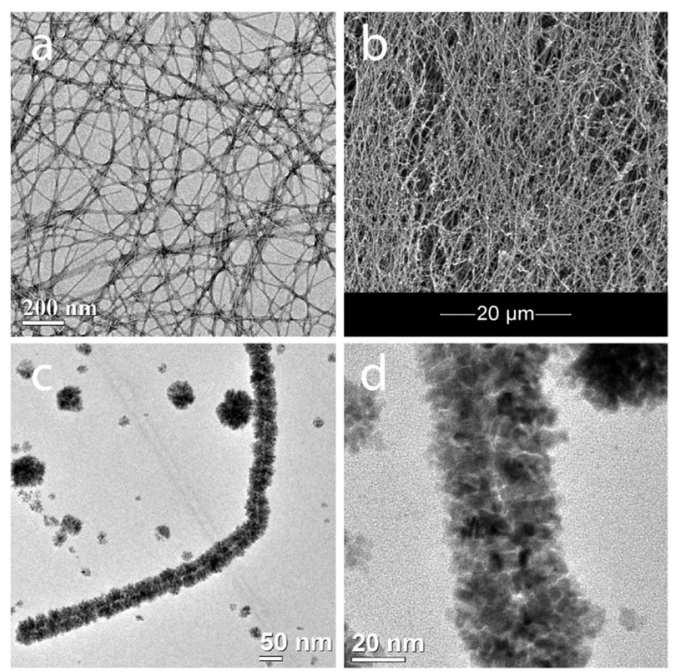

Fig. 1 (a) TEM image of the peptide nanofibers, (b) SEM image of the peptide nanofiber network, (c) and (d) TEM images of Pd nanoparticles on the peptide nanofibers.

At $\mathrm{pH}>6$, the PA molecules can self-assemble into nanofibers with a diameter of $c a .10 \mathrm{~nm}$ (Fig. 1a) directed by $\beta$-sheet structures (Fig. S3, ESI $\dagger$ ). A three-dimensional network of the PA nanofibers forms a self-supporting hydrogel at concentration of $1 \mathrm{wt} \%$ (Fig. $1 \mathrm{~b}$ and Fig. S4-S6, ESI $\dagger$ ). In this work, we exploited peptide nanofibers as a nanoscale template for formation of $\mathrm{Pd}^{0}$ nanoparticles. Following a multi-step reduction methodology, closely-packed one-dimensional palladium nanoparticles were grown on peptide nanofibers. $\mathrm{Pd}^{\mathrm{II}}$ ions accumulated on the peptide nanofibers due to their affinity to imidazole residues. After peptide nanofiber formation at $\mathrm{pH} \mathrm{7,} \mathrm{palladium}$ solution was added to the peptide nanofiber hydrogel and the mixture was left at room temperature overnight to enable interaction of the ions with the imidazole moiety of histidine residues in the peptide. Later, a reducing agent $(\mathrm{L}-(+)$-ascorbic acid) was added to the mixture. After the first reduction, the $\mathrm{Pd}^{\mathrm{II}}$ ion amount was increased for second and third reduction cycles by increasing the $\mathrm{Pd} /$ peptide molar ratio. Nanoparticle formation on the peptide template was inadequate in the first reduction cycle (Fig. S7, ESI $\dagger$ ). After the third cycle, coating of peptide nanofibers with closely packed palladium nanoparticles was clearly observed (Fig. 1c and d). To remove peptide molecules without $\mathrm{Pd}$, the sample was filtered through a cellulose membrane with $0.2 \mu \mathrm{m}$ cut off. Filtration was found to be the most effective and easiest way of eliminating the excess peptide without disturbing the integrity of the catalyst assembly. To the best of our knowledge, this type of highly ordered Pd nanostructures was obtained for the first time by use of a peptide nanofiber template methodology.

Metal nanoparticle loading capacity of the peptide nanofiber templates was assessed by thermogravimetric analysis (TGA). The Pd@Peptide sample was dried at $100{ }^{\circ} \mathrm{C}$ in an oven, and heated to $550{ }^{\circ} \mathrm{C}$. The inorganic content was found to be $42.5 \%$ (Fig. S8, ESI $\dagger$ ). The crystalline structure of the Pd@Peptide sample was analyzed by X-ray diffractometry (XRD). The dominant surface is $\{111\}$. $\mathrm{Pd}\{111\}$ is the lowest energy facet and the most stable facet of $\mathrm{Pd} .{ }^{18}$ The presence of a broad Pd $\{111\}$ pattern expresses low periodic and atomic order of Pd nanoparticles, because as grain size decreases, its XRD pattern broadens (Fig. S9, ESI $\dagger$ ). Suzuki coupling reactions were performed as a model reaction to determine catalytic activity of the $\mathrm{Pd}$ nanostructures on the peptide nanofibers. Water was used for coupling reactions as an attractive green and cheap solvent. ${ }^{19} \mathrm{We}$ optimized Pd@Peptide loading as 1.5 mol\% (Table S4, ESI $\dagger$ ) and reaction conditions for iodobenzene (Table S1, entry 1, $\mathrm{ESI} \dagger$ ) in water at room temperature. The reaction was completed in less than 4 h with $99 \%$ biphenyl conversion (Table S1, entry 1 , ESI $\dagger$ ). Mixing ethanol, which is another environmentally friendly solvent, expedited the reaction rate four folds (Table S1, entry 2, ESI $\dagger$ ). The rate enhancement is potentially due to improved solubility of the starting materials in the water-ethanol mixture. ${ }^{20}$ Various aryl iodides were employed to investigate the diversity of aryl iodides tolerated in Suzuki-Miyaura coupling reactions with aryl boronic acids (Table S1, ESI $\dagger$ ).

The Pd@Peptide nanocatalyst revealed excellent catalytic activity towards diverse substrates under the optimized reaction conditions (Table 1, entry 1). When activated aryl iodide (1-fluoro-4-iodobenzene) was used instead of iodobenzene, the biaryl product (Table 1, entry 2) was obtained in only $1 \mathrm{~h}$ in $99 \%$ yield. It should also be noted that the corresponding biaryl product was obtained in only $2 \mathrm{~h}$ in quantitative yield when deactivated 1-iodo-4-methoxybenzene (Table 1, entry 3) was used.The Pd@Peptide nanocatalyst can activate 4-iodoanisol efficiently. Replacing phenyl boronic acid with 4'-methoxybiphenyl-4-ylboronic acid demonstrated interesting results. 4'-methoxybiphenyl-4-ylboronic acid reacted with iodobenzene, 1-fluoro-4-iodobenzene (activated), and 1-iodo-4-methoxybenzene (deactivated) and yielded the desired products (Table 1, entries 5, 6, and 7) in high yields in only $1 \mathrm{~h}$. The electronwithdrawing and electron-donating groups in aryl iodides did not have considerable effect on the reaction rates. We tested several conditions for aryl bromides as summarized in Table S1 (ESI $\dagger$ ). It was previously reported that activation of the $\mathrm{Br}-\mathrm{C}$ bond is more challenging than the $\mathrm{I}-\mathrm{C}$ bond. ${ }^{21}$ Only a trace amount of the biphenyl product was observed for bromobenzene in water at room temperature (Table 1, entry 3) and at $80{ }^{\circ} \mathrm{C}$ (Table 1 , entry 4). The nature of the base is reported to be crucial in different Suzuki coupling reactions. ${ }^{22}$ Therefore, the base was changed from $\mathrm{K}_{3} \mathrm{PO}_{4}$ to $\mathrm{K}_{2} \mathrm{CO}_{3}$. However, it did not improve the reactions for bromobenzene derivatives (Table S1, entries 5 and 6, ESI $\dagger$ ).

Table 1 Suzuki-Miyaura coupling of aryl iodides with Pd@Peptide nanocatalyst ${ }^{a}$

\begin{tabular}{lllll} 
& & & Time (h) & Conversion $^{b}(\%)$ \\
\hline Entry & $\mathrm{R}_{1}$ & $\mathrm{R}_{2}$ & $\mathrm{H}_{2} \mathrm{O}$, r.t. $\mathrm{K}_{3} \mathrm{PO}_{4}$ & Time \\
\hline 1 & $\mathrm{H}$ & $\mathrm{H}$ & 4 & 99 \\
2 & $\mathrm{~F}$ & $\mathrm{H}$ & 1 & 99 \\
4 & $\mathrm{OMe}$ & $\mathrm{H}$ & 2 & 99 \\
5 & $\mathrm{H}$ & $\mathrm{OMe}$ & 1 & 85 \\
6 & $\mathrm{~F}$ & $\mathrm{OMe}$ & 1 & 99
\end{tabular}

${ }^{a}$ Reaction conditions: aryl iodide $(0.5 \mathrm{mmol})$, arylboronic acid (0.75 mmol), Pd@Peptide (1.5 mol\% with respect to aryl iodide concentration), $\mathrm{K}_{3} \mathrm{PO}_{4}$ (2.0 equiv.), solvent $(4 \mathrm{~mL}) .{ }^{b}$ The reaction yield was determined by GC-MS (Fig. S21-S30, ESI). 
Table 2 Suzuki-Miyaura coupling of aryl bromides with Pd@Peptide nanocatalyst ${ }^{a}$

\begin{tabular}{|c|c|c|c|c|}
\hline Entry & $\mathrm{R}_{1}$ & $\mathrm{R}_{2}$ & Time (h) & Conversion $^{c}(\%)$ \\
\hline 1 & $\mathrm{H}$ & $\mathrm{H}$ & 4 & 99 \\
\hline 2 & $\mathrm{NO}_{2}$ & $\mathrm{H}$ & 24 & 99 \\
\hline $3^{b}$ & $\mathrm{NO}_{2}$ & $\mathrm{H}$ & 12 & 99 \\
\hline 4 & $\mathrm{OMe}$ & $\mathrm{H}$ & 24 & 99 \\
\hline 5 & $\mathrm{H}$ & $\mathrm{OMe}$ & 4 & 83 \\
\hline
\end{tabular}

${ }^{a}$ Reaction conditions: aryl bromide $(0.5 \mathrm{mmol})$, arylboronic acid (0.75 mmol), Pd@Peptide ( $1.5 \mathrm{~mol} \%$ with respect to aryl bromide concentration), $\mathrm{NaOH}$ (2.0 equiv.), water $(5 \mathrm{~mL}$ ) at room temperature. ${ }^{b} 10 \%$ ethanol was used. ${ }^{c}$ The reaction yield was determined by GC-MS (Fig. S43-S50, ESI).

Inspired from the four fold rate enhancement in entry 2 (Table S1, ESI $\dagger$ ), we mixed ethanol as a green, organic and water miscible solvent with water. When ethanol was mixed with water in a $1: 1$ ratio, some rate enhancement was observed at room temperature (Table S1, entry 8, ESI $\dagger$ ). Increasing temperature to $80{ }^{\circ} \mathrm{C}$ yielded the desired product in almost quantitative yield in less than $4 \mathrm{~h}$. High activation of the $\mathrm{Br}-\mathrm{C}$ bond and low solubility of bromobenzene in water caused low catalytic activity due to limited interaction between the reactants. The Pd@Peptide nanocatalyst revealed high catalytic activity in the water-ethanol mixture for $\mathrm{Br}-\mathrm{C}$ bond activation. Interestingly, most of the Suzuki coupling reactions were completed in almost $2 \mathrm{~h}$ with very high conversions regardless of the presence of electron donating and withdrawing groups in the reactant molecules (Table S2, ESI $\dagger$ ). Moderate conversion $(57 \%)$ in a styrene derivative (Table S2, entry 7 , ESI $\dagger$ ) is caused by formation of by-products due to Heck reaction. The substituted styrene can produce both Suzuki and Heck coupling products in the presence of a base.

In addition, we optimized conditions for aryl bromides in water at room temperature. The $\mathrm{NaOH}$ was used as a base (Table S1, entry 10, ESI $\dagger$ ). The Pd@Peptide nanocatalyst showed excellent catalytic activity with aryl bromides in water at room temperature (Table 2). Most of the reactions were completed with $99 \%$ yield. We also investigated the effect of different groups attached to the aryl bromide. The electron withdrawing (Table 2, entry 2) and electron donating groups (Table 2, entry 4) present in bromobenzene demonstrated similar results. Interestingly, when $10 \%$ ethanol (Table 2, entry 3) was added as a co-solvent, two folds rate enhancement was observed due to increased solubility of the reactants in ethanol. The 4'-methoxybiphenyl-4-ylboronic acid also showed high yield $(83 \%)$ when reacted with bromobenzene (Table 2, entry 5). The Pd@Peptide nanocatalyst also showed excellent catalytic activity even with the least reactive chlorobenzene derivative ${ }^{22}$ at room temperature in water (Table S1, entry $11, \mathrm{ESI} \dagger)$.

Isolation of the catalysts from the reaction mixture and using them in successive reactions make the chemical process cost effective on the industrial scale and prevent accumulation of mass palladium waste. Therefore, we further evaluated recyclability of our catalyst under harsh conditions (in an ethanol-water mixture at $80{ }^{\circ} \mathrm{C}$ ). The catalyst was reused in consequent reactions and showed efficient catalytic activity even after fifth use (95\% product conversion, Table S3, ESI $\dagger$ ). No considerable change was observed in the structural integrity of the nanocatalyst when the Pd@Peptide nanocatalyst was treated under the same reaction conditions (Fig. S10, ESI $\dagger$ ). Developing efficient and green catalysts is important for new technologies to eliminate waste, to avoid using hazardous solvents and reagents, and to possess high recyclability. Here, we demonstrated a bioinspired peptide amphiphile nanofiber template for formation of one-dimensional Pd nanostructures. The Pd@Peptide nanocatalyst system provided high catalytic activity in Suzuki coupling reactions under environmentally friendly conditions. Moreover, the nanocatalyst can be easily isolated and reused at least 5 times in consecutive reactions without significant loss in activity and structural integrity. We believe that this novel approach can find applications in many industrially important catalytic processes under environmentally friendly conditions.

M. A. K., R. G., and R. G. are supported by TÜBÎTAKBÎDEB fellowship. This work is partially supported by grants; TUBÎTAK 109T603, TUBA-GEBIP, and FP7 Marie Curie IRG. We thank M. Guler for help in TEM and Z. Erdogan for help in LC-MS and GC-MS.

\section{Notes and references}

1 B. F. G. Johnson, Top. Catal., 2003, 24, 147-159.

2 T. Tagata and M. Nishida, J. Org. Chem., 2003, 68, 9412-9415.

3 D. Astruc, Tetrahedron: Asymmetry, 2010, 21, 1041-1054.

4 C. Ornelas, A. K. Diallo, J. Ruiz and D. Astruc, Adv. Synth. Catal., 2009, 351, 2147-2154.

5 B. Yuan, Y. Pan, Y. Li, B. Yin and H. Jiang, Angew. Chem., 2010, 122, 4148-4152.

6 C. M. Crudden, M. Sateesh and R. Lewis, J. Am. Chem. Soc., 2005, 127, 10045-10050.

7 S. Patra, B. Viswanath, K. Barai, N. Ravishankar and N. Munichandraiah, ACS Appl. Mater. Interfaces, 2010, 2, 2965-2969.

8 H. F. Lang, R. A. May, B. L. Iversen and B. D. Chandler, J. Am. Chem. Soc., 2003, 125, 14832-14836.

9 I. T. Horvath, Green Chem., 2008, 10, 1024-1028.

10 S. Minakata and M. Komatsu, Chem. Rev., 2009, 109, 711-724.

11 B. Yuan, Y. Pan, Y. Li, B. Yin and H. Jiang, Angew. Chem., Int. Ed., 2010, 49, 4054-4058.

12 C.-W. Yang, K. Chanda, P.-H. Lin, Y.-N. Wang, C.-W. Liao and M. H. Huang, J. Am. Chem. Soc., 2011, 133, 19993-20000.

13 E. Dujardin, C. Peet, G. Stubbs, J. N. Culver and S. Mann, Nano Lett., 2003, 3, 413-417.

14 H. I. Ryoo, J. S. Lee, C. B. Park and D. P. Kim, Lab Chip, 2011, 11, 378-380.

15 H. Acar, R. Garifullin and M. O. Guler, Langmuir, 2011, 27, 1079-1084.

16 H. Ceylan, S. Kocabey, A. B. Tekinay and M. O. Guler, Soft Matter, 2012, 8, 3929-3937.

17 P. Tsiveriotis and N. Hadjiliadis, Coord. Chem. Rev., 1999, 192, 171-184.

18 Y. Xia, Y. Xiong, L. Byungkwon and S. E. Skrabalak, Angew. Chem., Int. Ed., 2009, 48, 60-103.

19 B. Cornils and W. A. Herrmann, Aqueous-Phase Organometallic Catalysis: Concepts and Applications, Wiley-VCH, 2004.

20 H. Bernsmann, M. van den Berg, R. Hoen, A. J. Minnaard, G. Mehler, M. T. Reetz, J. G. De Vries and B. L. Feringa, J. Org. Chem., 2005, 70, 943-951.

21 N. Miyaura and A. Suzuki, Chem. Rev., 1995, 95, 2457-2483.

22 B. Z. Yuan, Y. Y. Pan, Y. W. Li, B. L. Yin and H. F. Jiang, Angew. Chem., Int. Ed., 2010, 49, 4054-4058. 